\title{
Genetic Relationship of Stripe Rust Resistance Genes Yr34 and Yr48 in Wheat and Identification of Linked KASP Markers
}

N. Qureshi, H. S. Bariana, P. Zhang, R. McIntosh, and U. K. Bansal, ${ }^{\dagger}$ The University of Sydney Plant Breeding Institute, Faculty of Science, Cobbitty, NSW 2570, Australia; D. Wong and M. J. Hayden, Department of Economic Development, Jobs, Transport and Resources, AgriBio Centre, La Trobe Research and Development Park, Bundoora, VIC 3083, Australia; J. Dubcovsky, Department of Plant Sciences, University of California, Davis 95616; and M. Shankar, Agriculture and Food, Department of Primary Industries and Regional Development, South Perth, WA 6151, Australia; and School of Agriculture and Environment, University of Western Australia, Crawley WA 6009, Australia

\begin{abstract}
The Australian continent was free from wheat stripe rust caused by Puccinia striiformis f. sp. tritici until exotic incursions occurred in 1979 and 2002. The 2002 incursion enabled the identification of a new stripe rust resistance gene (Yr34) in the advanced breeding line WAWHT2046. In this study, we developed and validated markers closely linked with $\operatorname{rr34}$, which is located in the distal region in the long arm of chromosome 5A. Four kompetitive allele-specific polymerase chain reaction (KASP) and three sequencetagged site (STS) markers derived from the International Wheat Genome Sequencing Consortium RefSeq v1.0 scaffold-77836 cosegregated with Yr34. Markers sun711, sun712, sun725, sunKASP_109, and sunKASP_112 were shown to be suitable for marker-assisted selection in a validation panel of 71 Australian spring wheat genotypes, with the exception of cultivar Orion that

carried the Yr34-linked alleles for sunKASP_109 and sunKASP_112. Markers previously reported to be linked with adult plant stripe rust resistance gene Yr48 also cosegregated with $\mathrm{Yr} 34$. Wheat genotypes carrying $\mathrm{Yr} 34$ and Yr48 produced identical haplotypes for the Yr34-linked markers identified in this study and those previously reported to be linked with $Y r 48$. Phenotypic testing of genotypes carrying $\mathrm{Yr} 34$ and $\mathrm{Yr} 48$ showed that both genes conferred similar seedling responses to pre-2002 and post-2002 P. striiformis f. sp. tritici pathotypes. Further testing of $600 \mathrm{~F}_{2}$ plants from a cross between WAWHT2046 and RIL143 (Yr48) with P. striiformis f. sp. tritici pathotype $134 \mathrm{E} 16 \mathrm{~A}+\mathrm{Yr} 17+\mathrm{Yr} 27+$ failed to reveal any susceptible segregants. Our results strongly suggest that $Y r 34$ and $Y r 48$ are the same gene, and that $Y r 48$ should be considered a synonym of $Y r 34$.
\end{abstract}

Stripe rust is a widely distributed disease of wheat, occurring in almost all continents, except Antarctica (Chen 2005). It is relatively new in Australia, with the first incursion of Puccinia striiformis $\mathrm{f}$. sp. tritici pathotype 104 E137A- occurring in 1979 in eastern Australia (O'Brien et al. 1980). Since then, 21 variants of the original pathotype have been reported, through acquisition of virulence for stripe rust resistance genes $\mathrm{YrA}, \mathrm{Yr} 6, \mathrm{Yr} 7$, and $\mathrm{Yr} 17$ either individually or sequentially in different combinations. In 2002, another incursion occurred in Western Australia (WA). It was pathotyped as 134 E16A+ and named as the "WA pathotype". This pathotype differed from the eastern Australian pathotypes and appeared to be similar to those reported by Chen (2005) in the United States and Hovmøller and Bayles (2005) in Europe. The key feature of this pathotype compared with the earlier group was its combined virulence for genes $\operatorname{Yr} 8$ and $Y r 9$ and avirulence for $Y r 3, Y r 4$, and $Y r 34$ (Bariana et al. 2006; Wellings et al. 2003). Since the original incursion, several new variants from the WA pathotype involving virulence for $\operatorname{Yr} 10, \operatorname{Yr} 17, \mathrm{Yr} 24 / \mathrm{Yr} 26$, $Y r J, Y r T$, and $Y r 27$ have been detected (Singh et al. 2010; Wellings 2007).

The incursion of the WA pathotype in Australia resulted in high yield losses and increased expenditure on chemical control (AU $\$ 40$ to 90 million) during the crop seasons of 2003 to 2005 (Wellings 2007). Several Australian cultivars that carried resistance to pre-2002 pathotypes were susceptible to the WA pathotype, while cultivar Rubric and the advanced breeding line WAWHT2046 from the Department of Primary Industries and Regional Development, WA expressed higher levels of resistance (Bariana et al. 2006). Rubric was shown to carry Yr4 (Bansal et al. 2010), whereas the resistance gene carried by WAWHT2046 was mapped 12.2 centimorgans (cM) distal to the awn inhibitor locus $B 1$ in the long arm of chromosome $5 \mathrm{~A}$ and was formally named Yr34 by Bariana et al. (2006) using a WAWHT2046/Carnamah

${ }^{\dagger}$ Corresponding author: U. K. Bansal; E-mail: urmil.bansal@sydney.edu.au Accepted for publication 18 September 2017.

@ 2018 The American Phytopathological Society doubled-haploid (DH) population. Yr34 remains effective against all variants of the WA pathotype detected thus far in Australia.

The advent of next-generation DNA sequencing and highthroughput marker genotyping has played a significant role in speeding up the process of developing trait-linked markers and identifying causal genes for trait variation. Several technologies now exist for high-density genotyping, including Diversity Array Technology (DArT; www.diversityarrays.com), Illumina iSelect single-nucleotide polymorphism (SNP) array (Wang et al. 2014), and genotyping by sequencing (He et al. 2014). Such technologies, in combination with the International Wheat Genome Sequencing Consortium (IWGSC) assembly for common wheat variety Chinese Spring and the more recent release of the annotation for the wheat genome (https://wheat-urgi. versailles.inra.fr/About-us/News/IWGSC-RefSeq-v1.0-annotation-isnow-available), now make it possible to physically localize traitlinked polymorphism in the wheat genome to develop new markers to saturate a genomic region of interest, and to prioritize candidate genes for functional analysis. For example, markers linked with $\mathrm{Sr} 56$ and $\mathrm{Lr} 52 / \mathrm{Yr} 47$ were developed using these genomic resources (Bansal et al. 2014; Qureshi et al. 2017).

Despite the effectiveness of $Y r 34$ against all post-2002 pathotypes, this gene has not been widely used in Australian breeding programs, presumably due to expression of high seedling infection type (IT) $23 \mathrm{C}-33 \mathrm{C}$ and the unavailability of closely linked molecular markers. Adult plant stripe rust resistance gene $\mathrm{Yr} 48$ was located in chromosome 5AL by Lowe et al. (2011), and these workers placed it distal to $\mathrm{Yr} 34$ based on a comparison of their map with that presented by Bariana et al. (2006).

This study was planned to produce a detailed map of the $Y r 34$ region on the long arm of chromosome $5 \mathrm{~A}$ using various genomic resources to identify closely linked markers for effective pyramiding of this gene with other marker-tagged rust resistance genes, and to study the relationship between $\operatorname{Yr} 34$ and $\operatorname{Yr} 48$.

\section{Material and Methods}

Plant material. The WAWHT2046/Carnamah DH population of 106 lines from Bariana et al. (2006) was used in this study. Another WAWHT2046/Avocet S-derived recombinant inbred line (RIL) population (68 lines) was used to validate the association of Yr34-linked 
markers. A set of 71 Australian cultivars was used to validate the utility of closely linked markers for marker-assisted selection (MAS) of Yr34 and Yr48 in breeding programs.

An $\mathrm{F}_{2}$ population derived from a cross between WAWHT2046 (Yr34) and RIL143 (Yr48; derived from the cross UC1110/PI610750) (Lowe et al. 2011) was developed to determine allelism between $\operatorname{Yr} 34$ and $\mathrm{Yr} 48$.

Greenhouse tests. The DH and RIL populations were screened under greenhouse conditions using $P$. striiformis $\mathrm{f}$. sp. tritici pathotype 134 E16A+Yr17+Yr27+ (University of Sydney accession 617). Eight seeds of each line and four lines per pot were sown in 9-cm pots filled with a potting mix comprising pine bark and river sand (2:1). Parents WAWHT2046, Carnamah, and Avocet $S$ were included as controls in each experiment. After sowing, pots were placed in a rust-free microclimate room set at $20^{\circ} \mathrm{C}$. Seedlings were inoculated at the two-leaf stage with urediniospores of $P$. striiformis f. sp. tritici pathotype $134 \mathrm{E} 16 \mathrm{~A}+\mathrm{Yr} 17+\mathrm{Yr} 27+$. The urediniospores were suspended in light mineral oil Isopar-L (https://www.ascc.net.au/) and atomized onto seedlings using an aerosol pressure pack. Inoculated seedlings were incubated in a dark dew chamber set at $9^{\circ} \mathrm{C}$ for $24 \mathrm{~h}$ and then transferred to a microclimate room set at $17^{\circ} \mathrm{C}$. Stripe rust responses were assessed 14 to 16 days after inoculation using the 0 to 4 infection type (IT) scale outlined by McIntosh et al. (1995), where IT 0 to 3 were considered resistant and $3^{+}$and 4 were considered susceptible.

The Yr48-carrying genotype RIL143 (Lowe et al. 2011) was also tested at the two-leaf stage with post-2002 and pre-2002 pathotypes $134 \mathrm{E} 16 \mathrm{~A}+\mathrm{Yr} 17+\mathrm{Yr} 27+$ and $110 \mathrm{E} 143 \mathrm{~A}+$, respectively, along with WAWHT2046, and susceptible controls Carnamah and Morocco to compare pathotypic specificities of these genes.

Field tests. The WAWHT2046/Carnamah DH population was grown at the Karalee and Lansdowne experimental field sites of the Plant Breeding Institute, Cobbitty, NSW, Australia and the WAWHT2046/ Avocet S RIL population at the Horse Research Unit site as 1-m rows. The parents were sown along with each population. A 30-cm strip of the susceptible genotype Nyabing 3 was planted as a spreader after each block of 35 experimental rows to facilitate uniform disease development. The spreader rows were inoculated three times with $P$. striiformis f. sp. tritici pathotype $134 \mathrm{E} 16 \mathrm{~A}+\mathrm{Yr} 17+\mathrm{Yr} 27+$ at weekly intervals from the last week of July. Stripe rust responses were scored using a 1 to 9 scale (Bariana et al. 2007) after flag leaf emergence. Both populations were scored for segregation at the awn inhibitor locus $B 1$.

DNA extraction and quantification. Genomic DNA was extracted from 2-week-old seedlings of both populations and their parents using the modified cetyltrimethylammonium bromide procedure described in Bansal et al. (2014). DNA was quantified using a Nanodrop ND-1000 spectrophotometer (Nanodrop Technologies) and diluted to a concentration of $30 \mathrm{ng} / \mu \mathrm{l}$.

Simple sequence repeat and sequence-tagged site genotyping. Previously reported simple sequence repeat (SSR) and sequencetagged site (STS) markers ( $g w m 410, c f a 2149$, gpw2181, wPt-7061, gwm291, SNF-A2, gwm595, and gwm6) were tested on both populations (Lowe et al. 2011; Röder et al. 1998; Somers et al. 2004; Sourdille et al. 2001) (http://maswheat.ucdavis.edu/protocols/index.htm) following the procedure described by Bansal et al. (2014).

SNP genotyping. Selective genotyping using the iSelect $90 \mathrm{~K}$ Infinium SNP assay (Wang et al. 2014) on eight homozygous resistant (Yr34Yr34) and eight homozygous susceptible (yr34yr34) lines from the WAWHT2046/Carnamah DH population was undertaken to identify Yr34-linked SNP. Sequences flanking the linked SNP (Wang et al. 2014) were used to design kompetitive allele-specific polymerase chain reaction (KASP) assays with two allele-specific forward primers and one common reverse primer (https://www. lgcgroup.com/kasp/\#.WUyFu-uGOUk).

KASP genotyping. KASP assays were performed in $8-\mu 1$ reaction volumes containing $165 \mathrm{nM}$ each specific forward primer, $412 \mathrm{nM}$ common reverse primer, $90 \mathrm{ng}$ of genomic DNA, and $1 \times$ KASP buffer mix containing $\mathrm{MgCl}_{2}$, Taq polymerase, dNTP, universal FAM and HEX fluorescence resonance energy-transmitted cassettes, and ROX reference dye (KBioscience). Polymerase chain reaction
(PCR) thermocycling was performed using a Bio-Rad CFX96 Touchdown real-time PCR system with an initial denaturation step of $94^{\circ} \mathrm{C}$ for $15 \mathrm{~min}$, followed by 9 touchdown cycles at $94^{\circ} \mathrm{C}$ for $20 \mathrm{~s}$ and $61^{\circ} \mathrm{C}$ for $1 \mathrm{~min}$ (dropping $0.6^{\circ} \mathrm{C}$ per cycle), and 38 cycles at $94^{\circ} \mathrm{C}$ for $20 \mathrm{~s}$ and $55^{\circ} \mathrm{C}$ for $1 \mathrm{~min}$. SNP genotype calling was performed using Bio-Rad CFX Manager software (Bio-Rad).

STS marker development and genotyping. DArT marker $w P t-7061$, previously reported to be linked with $Y r 48$, was used in BlastN queries against the genome sequence assembly of cultivar Chinese Spring (https://urgi.versailles.inra.fr/blast/?dbgroup= wheat_all\&program=blastn). Scaffold-77836, carrying the linked markers, was used to design primers with Primer3 v4.0 software (Koressaar and Remm 2007; Untergasser et al. 2012) for amplification of STS markers from the parental lines WAWHT2046 and Carnamah. The STS amplification products were checked for size variation on agarose gels and products not revealing polymorphism were Sanger sequenced at the Australian Genome Research Facility (www.agrf.org. $\mathrm{au}$ ) and compared for nucleotide variation using Sequencher software (www.genecodes.com). SNP identified in STS sequences were used to design KASP markers using Batchprimer3 software (http://probes.pw. usda.gov/batchprimer3/). STS and KASP markers were named with the prefix sun and sunKASP, respectively (sun = Sydney University), followed by consecutive numbers. STS and KASP markers showing polymorphism between the parental genotypes were genotyped in both populations.

STS markers were amplified by PCR in $25-\mu$ l reaction volumes containing $40 \mathrm{ng}$ of genomic DNA, $200 \mathrm{mM}$ dNTPs, $1 \times$ Immolase PCR buffer containing $1.5 \mathrm{mM} \mathrm{MgCl} 2$ and $100 \mathrm{nM}$ each forward and reverse primers, and $0.02 \mathrm{U}$ of Immolase DNA polymerase (Bioline). Thermal cycling conditions comprised a touchdown profile consisting of an initial denaturation at $95^{\circ} \mathrm{C}$ for $10 \mathrm{~min}$; followed by $92^{\circ} \mathrm{C}$ for $30 \mathrm{~s}, 65^{\circ} \mathrm{C}$ (with a $1^{\circ} \mathrm{C}$ drop per cycle) for $30 \mathrm{~s}$, and $72^{\circ} \mathrm{C}$ for $30 \mathrm{~s}$ for 5 cycles; then, 35 cycles of $30 \mathrm{~s}$ at $92^{\circ} \mathrm{C}, 40 \mathrm{~s}$ at $60^{\circ} \mathrm{C}$, and $50 \mathrm{~s}$ at $72^{\circ} \mathrm{C}$; and a final extension step of $72^{\circ} \mathrm{C}$ for $10 \mathrm{~min}$. PCR product ( $3 \mu \mathrm{l}$ of each marker) was visualized on a $2 \%$ agarose gel stained with GelRed (Biotium).

Statistical analysis and mapping. A $\chi^{2}$ analysis was performed to test goodness-of-fit of the observed segregation among the $\mathrm{DH}$ and RIL populations with the expected genetic ratios for hypothesized genetic models. Genetic linkage maps were constructed using MapManager software, version QTXb20 (Manly et al. 2001), and the Kosambi mapping function for conversion of recombination fractions to centimorgans (Kosambi 1943). The final linkage map was drawn using MapChart software (Voorrips 2002).

\section{Results}

Assessment of rust responses. WAWHT2046 expressed IT 23C33C against $P$. striiformis f. sp. tritici pathotype 134 E16+Yr17+ Yr27+, whereas the susceptible genotypes Carnamah and Avocet $S$ produced IT $3^{+}$(Fig. 1A). When tested in the greenhouse against this pathotype, 61 WAWHT2046/Carnamah DH lines were moderately resistant (IT 23C-3C) and 45 lines were susceptible (IT $3^{+}$), whereas 45 WAWHT2046/Avocet S RIL displayed IT 12C-23C and 23 lines expressed IT $3^{+}$(Table 1 ). A $\chi^{2}$ analysis of the segregation data for the DH population conformed to monogenic segregation, whereas the WAWHT2046/Avocet S RIL population showed a significant deviation from a 1:1 ratio (Table 1). The skewness observed in the RIL population presumably resulted from differential loss of susceptible lines during generation advancement of the RIL population.

When scored under field conditions, WAWHT2046 and Carnamah produced stripe rust responses of 2 and 6, respectively, on the 1 to 9 scale and Avocet $S$ was scored 9. Stripe rust responses among the DH lines varied from 2 to 8, and from 2 to 9 among the RIL population. Adult plant stripe rust response variation in both populations indicated the involvement of adult plant resistance genes in addition to the $\mathrm{Yr} 34$ scored at the seedling stage. Stripe rust responses for $\mathrm{DH}$ lines and RIL carrying Yr34 ranged from 2 to 5, indicating that this gene alone expressed an intermediate level of resistance.

WAWHT2046 carries the awn inhibitor allele $B 1$ and its awns are less than $2 \mathrm{~cm}$ long (tip-awned), whereas Carnamah is fully awned. 
Assessment of both populations for segregation at the $B 1 / b 1$ locus showed that the tip-awned phenotype was associated with resistance. Among the DH population, 60 lines were tip-awned and 45 lines were awned. One awned DH line showed a resistant response. The RIL population showed segregation that was skewed toward tipawned; 45 RIL were tip-awned and 22 awned. One tip-awned and susceptible recombinant was also observed in this population (Table 1).

Genetic mapping. Selective genotyping of eight resistant and eight susceptible WAWHT2046/Carnamah DH lines identified 33 SNP linked with Yr34. The linked SNP were converted into KASP markers and tested on the parental genotypes and three resistant and three susceptible DH lines. KASP assays showing scorable cluster patterns were tested on the entire DH population. Of the 20 KASP markers listed in Table 2, 19 were incorporated into the WAWHT2046/Carnamah map (Fig. 2). Only four KASP markers (KASP_2837, KASP_2838, KASP_47624, and KASP_56756) were polymorphic when tested on the WAWHT2046/Avocet S RIL population. These markers were tested on the entire RIL population.

Eighteen STS markers were designed (Table 3) from scaffold77836, which contained the DArT marker $w P t-7061$ previously reported to be linked to $\mathrm{Yr} 48$ (Lowe et al. 2011). Nine of the STS markers ( $\operatorname{sun} 713, \operatorname{sun} 715, \operatorname{sun} 717, \operatorname{sun} 719, \operatorname{sun} 720, \operatorname{sun} 721, \operatorname{sun} 723, \operatorname{sun} 724$, and sun726) were monomorphic between the parental genotypes on an agarose gel and were subsequently Sanger sequenced. Markers sun 710 and sun 718 amplified multiple fragments in the parental genotypes, whereas $\operatorname{sun} 714, \operatorname{sun} 716$, sun722, and $\operatorname{sun} 727$ failed to amplify in WAWHT2046. Markers sun711, sun712, and sun725 were polymorphic between the parents (WAWHT2046 versus Carnamah and Avocet S) and were tested on both the DH and RIL populations.

Sanger sequencing of the nine STS markers not revealing amplicon size variation among the parental genotypes identified SNP variation in the amplicons produced by markers $\operatorname{sun} 713, \operatorname{sun} 717, \operatorname{sun} 719$, $\operatorname{sun} 724$, and $\operatorname{sun} 726$, whereas no sequence variation was observed for markers $\operatorname{sun} 715, \operatorname{sun} 720, \operatorname{sun} 721$, and $\operatorname{sun} 723$. Of the five KASP markers developed for SNP within the STS markers, four (sunKASP_109, sunKASP_110, sunKASP_112, and sunKASP_113) produced scorable polymorphic clusters among the parental genotypes WAWHT2046, Carnamah, and Avocet S and were tested on both populations (Table 4).

The WAWHT2046/Carnamah and WAWHT2046/Avocet S populations were also tested with markers gwm410, cfa2149, gpw2181, $w P t-7061, g w m 291, S N F-A 2, g w m 595$, and $g w m 6$, which were previously mapped to the distal part of chromosome 5AL (Lowe et al. 2011).

The final genetic linkage map for the WAWHT2046/Carnamah DH population comprised 34 markers (19 KASP markers derived from the 90K SNP map, 4 sunKASP markers derived from Sanger sequencing, 7 SSR, and 4 STS), and the map of the WAWHT2046/ Avocet S RIL population comprised 16 markers (4 SSR, 4 STS, 4 KASP markers derived from linked $90 \mathrm{~K}$ SNP, and 4 sunKASP markers derived from Sanger sequencing) (Fig. 2). Eleven markers $(\operatorname{sun} 711, \operatorname{sun} 712$, sun725, sunKASP_109, sunKASP_110, sunKASP_112, sunKASP_113, gwm410, cfa2149, gpw2181, and $w P t-7061)$ cosegregated with Yr34 in both populations. Marker $K A S P \_6988$ cosegregated with $Y r 34$ only in the DH population. The awn inhibitor locus $B 1$ mapped 1 and $0.7 \mathrm{cM}$ proximal to Yr34, whereas SSR marker gwm291 mapped 1.5 and $2.3 \mathrm{cM}$ proximal to B1 in WAWHT2046/Carnamah and WAWHT2046/Avocet S, respectively (Fig. 2). All cosegregating markers, except $c f a 2149$, were located in scaffold-77836 (Fig. 3).

Validation of Yr34-linked markers. Yr34-linked markers were tested on 71 Australian cultivars (Fig. 3). Markers sun712, cfa2149,

Table 1. Frequency distribution of lines in the WAWHT2046/Carnamah doubled-haploid (DH) and WAWHT2046/Avocet S recombinant inbred line (RIL) populations when tested against Puccinia striiformis f. sp. tritici pathotype $134 \mathrm{E} 16 \mathrm{~A}+\mathrm{Yr} 17+\mathrm{Yr} 27+$ and for segregation at the $B 1$ awn inhibitor locus

\begin{tabular}{lccccc}
\hline Population & IT $^{\mathbf{a}}$ & $\begin{array}{c}\text { Genotype } \\
\text { frequency }\end{array}$ & B1B1 & b1b1 & Total \\
\hline Carnamah/ & $23 \mathrm{C}-3 \mathrm{C}$ & Yr34Yr34 & 60 & 1 & 61 \\
WAWHT2046 $^{\mathrm{b}}$ & & & & & \\
& $3^{+}$ & $y r 34 y r 34$ & 0 & 45 & 45 \\
& Total & & 60 & 46 & 106 \\
WAWHT2046/Avocet Sc & $12 \mathrm{C}-23 \mathrm{C}$ & Yr34Yr34 & 45 & 0 & 45 \\
& $3^{+}$ & $y r 34 y r 34$ & 1 & 22 & 23 \\
& Total & Total & 46 & 22 & 68 \\
\hline
\end{tabular}

${ }^{a}$ Infection type.

${ }^{\mathrm{b}}$ For $\chi^{2}: \chi_{1: 1(B 1 \text { versus } b 1)}^{2}=1.85\left(P_{1 \mathrm{~d} . \mathrm{f}}>0.05\right), \chi_{1: 1(Y r 34 \text { versus } y r 34)}^{2}=2.42$ $\left(P_{1 \mathrm{~d} . \mathrm{f}}>0.05\right)$, and $\chi^{2} 1: 1: 1: 1(B 1$ versus $Y r 34)=106.30\left(P_{3 \mathrm{~d} . \mathrm{f}}>0.05\right)$.

${ }^{\mathrm{c}}$ For $\chi^{2}: \chi_{1: 1(B 1 \text { versus } b 1)}^{2}=8.47\left(P_{1 \text { d.f }}<0.05\right), \chi_{1: 1(Y r 34 \text { versus } y r 34)}^{2}=7.11$ $\left(P_{1 \mathrm{~d} . \mathrm{f}}<0.05\right)$, and $\chi_{1: 1: 1: 1\left(B 1 \text { versus } Y_{r 34}\right)}^{2}=79.65\left(P_{3 \mathrm{~d} . \mathrm{f}}<0.05\right)$.
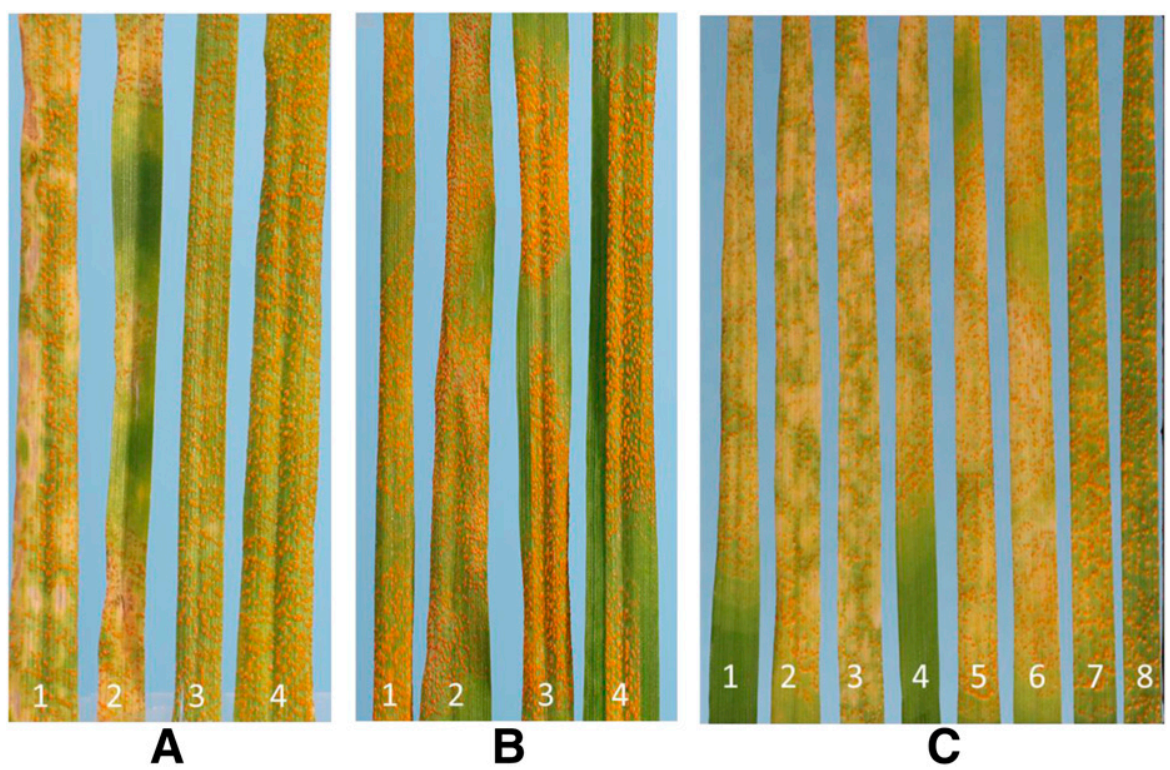

Fig. 1. Infection types at the two-leaf stage produced by 1: WAWHT2046, 2: Yr48 carrying RIL143, 3: Avocet S, and 4: Carnamah when tested with A, Puccinia striiformis f. sp. tritici pathotype $134 \mathrm{E} 16+\mathrm{Yr} 17+\mathrm{Yr} 27+;$ B, P. striformis f. sp. tritici pathotype $110 \mathrm{E} 143 \mathrm{~A}+$; and C, $\mathrm{F}_{2}$ plants (examples 1, 2, 3, 4), WAWHT2046 (5), RIL143 (6), Carnamah (7), and Morocco (8) inoculated with $P$. striiformis f. sp. tritici pathotype $134 \mathrm{E} 16 \mathrm{~A}+\mathrm{Yr} 17+\mathrm{Yr} 27+$. 
and $w P t-7061$ were codominant and $c f a 2149$ and $w P t-7061$ amplified additional fragments in the parental genotypes and test cultivars (Fig. 4). Markers sun711 and sun725 amplified a monomorphic product in all lines tested and a second product in the parental lines carrying Yr34 and Yr48. Markers gwm410 and gpw2181 behaved in the opposite manner, amplifying a monomorphic fragment in all lines tested but absent in the parental lines carrying $Y r 34$ and $Y r 48$ (Table 5). Of the KASP markers, only sunKASP_109 and sunKASP_112 gave clear genotyping results across the Australian cultivars, with both markers producing the Yr34-linked (A:A) alleles in cultivar Orion (Table 5). These results indicated that codominant markers sun712, cfa2149, sunKASP_109, and SunKASP_112 can be used for MAS of Yr34.

Relationship of Yr34 with $Y r 48$. Adult plant stripe rust resistance gene $\mathrm{Yr} 48$ was mapped on the distal region of chromosome 5AL (Lowe et al. 2011). When tested on the WAWHT2046/Carnamah DH and WAWHT2046/Avocet S RIL populations, all DNA markers reported to be linked to $\mathrm{Yr} 48$ cosegregated with $\mathrm{Yr} 34$. To assess the relationship between these genes, WAWHT2046 (Yr34) and RIL143 (carrying only $\mathrm{Yr} 48$ ) were tested at the two-leaf stage with $P$. striiformis f. sp. tritici pathotypes $134 \mathrm{E} 16+\mathrm{Yr} 17+\mathrm{Yr} 27+$ (post-2002) and 110 E143A+ (pre-2002) (Fig. 1A and B). RIL143 produced responses similar to WAWHT2046 with both pathotypes, suggesting that $Y r 34$ and $Y r 48$ are the same gene.

Tests on $600 \mathrm{~F}_{2}$ plants from a cross between WAWHT2046 (Yr34) and RIL143 (Yr48) with pathotype 134 E16A+Yr17+Yr27+ failed to detect variation for stripe rust response, indicating close linkage or allelism between these two genes. All plants produced IT 23C-3C (Fig. 1C). Furthermore, all Yr34-linked markers in the WAWHT2046/Carnamah and WAWHT2046/Avocet S populations produced the same alleles in the lines carrying $\mathrm{Yr} 34$ and $\mathrm{Yr} 48$ (RIL143) (Table 5). Genotyping of random KASP markers for different chromosomes on WAWHT2046, RIL143, and 48 randomly

Table 2. Kompetitive allele-specific polymerase chain reaction (KASP) markers developed for Yr34-linked single-nucleotide polymorphism (SNP) detected by iSelect 90K Infinium array selective genotyping

\begin{tabular}{|c|c|c|c|c|}
\hline KASP marker & SNP & Allele 1 primer ${ }^{\mathbf{a}}$ & Allele 2 primer ${ }^{b}$ & Common primer \\
\hline KASP_6988 & {$[\mathrm{T} / \mathrm{C}]$} & catgggaatgctccatgaatttgct & tatgggaatgctccatgaatttgcc & cttgatcagagaatcagatgttggaagat \\
\hline$K A S P \_26751$ & {$[\mathrm{~A} / \mathrm{G}]$} & tctcctaccctaatcctatca & tcttctcctaccetaatcctatcg & ttcggatttcggcttctgcgtcaa \\
\hline KASP_5003 & {$[\mathrm{A} / \mathrm{C}]$} & tatgaagatgtactgcccactcct & tgaagatgtactgcccactccg & tatatgtccaagccacctggtttcaaata \\
\hline$K A S P \_3334$ & {$[\mathrm{~A} / \mathrm{G}]$} & atgaaagccgtagcggat & tgctatgaaagccgtagcggac & cggtttcaaagtacttgagagatctctta \\
\hline$K A S P \_48690$ & {$[\mathrm{~T} / \mathrm{C}]$} & atagtatatataattagaaattctccttgtga & tatagtatatataattagaaattctccttgtgg & cacccacaatacaaacacaaagtttgactt \\
\hline KASP_38700 & {$[\mathrm{A} / \mathrm{C}]$} & gaaagcttggacgaggctcca & tgaaagcttggacgaggctccc & gcagggatttcatattgccaatcccat \\
\hline$K A S P \_2837$ & {$[\mathrm{~A} / \mathrm{G}]$} & acggtaagaagtgatagcgctatga & tggtaagaagtgatagcgctatgg & ctcaacaccaccacaatgatcaccaa \\
\hline$K A S P \_71385$ & {$[\mathrm{~A} / \mathrm{G}]$} & ccagaagagaaaaccatgtgatctgt & tcagaagagaaaaccatgtgatctgc & tccattttcggaattgtctcctgtctt \\
\hline KASP_56756 & {$[\mathrm{T} / \mathrm{C}]$} & ccatgcaaaataatcttatcattcgatca & tccatgcaaaataatcttatcattcgatcg & actaacttttctcatggggatcatcgttt \\
\hline$K A S P \_2838$ & {$[\mathrm{~T} / \mathrm{C}]$} & cgtcggtccatccgcga & tcgtcggtccatccgegg & atttgtctacgcggttagggttaatacat \\
\hline$K A S P \_14661$ & {$[\mathrm{~A} / \mathrm{G}]$} & aagtattgtagttttctagttctacatttctat & tgtattgtagtttctagttctacattctac & tggccaagctcaaacaattgaaacttcaa \\
\hline KASP_7282 & {$[\mathrm{A} / \mathrm{G}]$} & caggggtctctgcttcetcct & tggggtctctgcttcctccc & gtagacaaactactgctcgagccaa \\
\hline KASP_7014 & {$[\mathrm{A} / \mathrm{C}]$} & cctcggcggcetgtacgtt & tctcggcggectgtacgtg & cgatgccgagaatggcactgctt \\
\hline$K A S P \_23336$ & {$[\mathrm{~T} / \mathrm{C}]$} & agacaaggctaacgttgtcgagat & tgacaaggctaacgttgtcgagac & gcctctggtttcccgatggtgat \\
\hline$K A S P \_14680$ & {$[\mathrm{~T} / \mathrm{C}]$} & gaaactgtggcagaagtaccgca & taaactgtggcagaagtaccgcg & ggacgtggccgaagtaggcaat \\
\hline KASP_65128 & {$[\mathrm{T} / \mathrm{C}]$} & gatgtcgtattgcttgtagtcetgt & tatgtcgtattgcttgtagtcetgc & ccgagcttcccaaaggtgctgat \\
\hline$K A S P \_3323$ & {$[\mathrm{~T} / \mathrm{C}]$} & ccattctttaattcaacaaacattggtgatt & tcattctttaattcaacaaacattggtgatc & gcaattccaggctgatttgacaatatcat \\
\hline KASP_48095 & {$[\mathrm{T} / \mathrm{G}]$} & caaggaggtggtggtggecta & taggaggtggtggtggcetc & gcgtctaaggacatgaaagaacatcattt \\
\hline KASP_58284 & {$[\mathrm{T} / \mathrm{C}]$} & ccattctttaattcaacaaacattggtgatt & tcattctttaattcaacaaacattggtgatc & gcaattccaggctgatttgacaatatcat \\
\hline$K A S P \_47624$ & {$[\mathrm{~A} / \mathrm{C}]$} & gegcattctcgtgtccect & tgcgcattctcgtgtceceg & cacagccaggacatcgtcggta \\
\hline
\end{tabular}

a A1 primer labeled with FAM: GAAGGTGACCAAGTTCATGCT.

b A2 primer labeled with HEX: GAAGGTCGGAGTCAACGGATT.

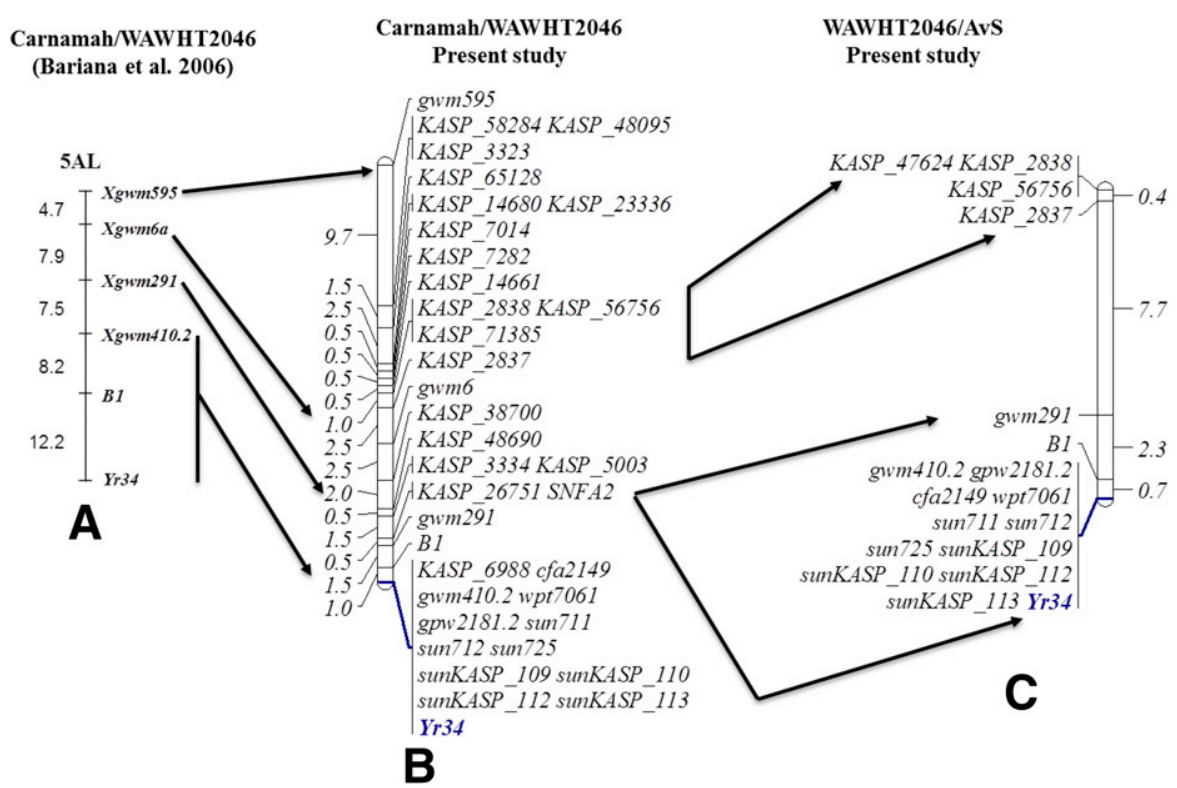

Fig. 2. Genetic linkage maps of chromosome 5AL. A, WAWHT2046/Carnamah doubled-haploid (DH) population; B, WAWHT2046/Carnamah DH population; and C, WAWHT2046/ Avocet $\mathrm{S}$ recombinant inbred line population. 
selected $\mathrm{F}_{2}$ plants confirmed the hybrid nature of the population. These results indicated that $Y r 34$ and $Y r 48$ are the same gene.

\section{Discussion}

The deployment of combinations of resistance genes is a strategy recommended to extend the durability of rust resistance genes deployed in commercial wheat varieties. Gene combinations help to enhance the durability of resistance by requiring multiple virulence changes in the pathogen. Breeding genotypes carrying resistance gene pyramids is greatly facilitated by the development of tightly linked molecular markers that can be used to select for the presence of multiple resistance genes in early generations. The purpose of this study was to develop and validate tightly linked, breeder-friendly molecular markers for MAS of $Y r 34$.

Selective genotyping performed on the WAWHT2046/Carnamah DH population identified multiple linked SNP on the $90 \mathrm{~K}$ iSelect array, many of which could be successfully converted into single-locus
KASP markers. The combination of genetic mapping of these KASP markers on the DH and RIL populations, and localization of flanking sequences for the linked 90K SNP markers in the IWGSC genome sequence assembly of cultivar Chinese Spring, positioned Yr34 near the telomere of 5AL. Indeed, marker KASP_6988 cosegregating with Yr34 was in the most distal scaffold (scaffold-77836) of 5AL. We utilized the sequence of scaffold-77836 to develop a series of markers that also cosegregated with $\operatorname{Yr} 34$ in both mapping populations. Of these markers, sun 712 was shown to be the best gel-based codominant marker for detecting and tracking the inheritance of $Y r 34$, because the 200-bp difference in alternate allele product size is easily differentiated (Fig. 4). KASP markers sunKASP109 and sunKASP112 would be equally suitable for MAS, except for the transfer of $Y r 34$ to cultivar Orion (Table 5).

Several markers previously reported to be linked with stripe rust resistance gene $\operatorname{Yr} 48$ (Lowe et al. 2011) were also physically located in the same region of chromosome 5AL as $\operatorname{Yr} 34$. Four KASP and

Table 3. Primer sequences and parental amplicon sizes for sequence-tagged site markers designed from International Wheat Genome Sequencing Consortium Refseq scaffold-77836

\begin{tabular}{|c|c|c|c|c|}
\hline Number & Marker & Primer sequence $\left(5^{\prime}-3^{\prime}\right)$ & WAWHT2046 (bp) & Carnamah/Avocet S (bp) \\
\hline \multirow[t]{2}{*}{1} & sun $710-F$ & gaacgtacggctcttcttgc & $1,137+700+250$ & $1,137+700+250$ \\
\hline & $\operatorname{sun} 710-R$ & cgaactacatgcgaagcaaa & & \\
\hline \multirow[t]{2}{*}{2} & sun711-F & cgaaacctgtcggtttgttt & $1,135+950$ & 1,135 \\
\hline & $\operatorname{sun} 711-R$ & ccctcaccaaatccaatgtc & & \\
\hline \multirow[t]{2}{*}{3} & $\operatorname{sun} 712-F$ & agagaagcgagcaactgagg & 900 & 1,150 \\
\hline & $\operatorname{sun} 712-R$ & gggtggggagtattggaaat & & \\
\hline \multirow[t]{2}{*}{4} & sun713-F & aaacccttggctggaacttt & 1,072 & 1,072 \\
\hline & $\operatorname{sun} 713-R$ & ggagccaaatggataagcaa & & \\
\hline \multirow[t]{2}{*}{5} & sun $714-F$ & tcacaaccaagacgagttgc & Null & 1,166 \\
\hline & $\operatorname{sun} 714-R$ & ttgggaaagcaaggaaaatg & & \\
\hline \multirow[t]{2}{*}{6} & sun $715-F$ & gtgtgttgccaaccettctt & 1,014 & 1,014 \\
\hline & sun $715-R$ & gttgccactttggttggagt & & \\
\hline \multirow[t]{2}{*}{7} & sun $716-F$ & atttttgcagatggctttgg & Null & 1,187 \\
\hline & $\operatorname{sun} 716-R$ & gttgccactttggttggagt & & \\
\hline \multirow[t]{2}{*}{8} & sun $717-F$ & tgtgatggctcagcgtagtc & 1,056 & 1,056 \\
\hline & $\operatorname{sun} 717-R$ & ttgttgaaattggggctttc & & \\
\hline \multirow[t]{2}{*}{9} & sun $718-F$ & ccccaatttcaacaatgtcc & $1,030+600+200$ & $1,030+600+200$ \\
\hline & sun $718-R$ & atgcgagctgcttcttcttc & & \\
\hline \multirow[t]{2}{*}{10} & sun $719-F$ & agaagcagctcgcatcagtt & 1,194 & 1,194 \\
\hline & $\operatorname{sun} 719-R$ & tttgggcgtgccttatatc & & \\
\hline \multirow[t]{2}{*}{11} & sun $720-F$ & atcggataaaaggcagcgta & 1,053 & 1,053 \\
\hline & $\operatorname{sun} 720-R$ & cctaggttgaccccgttttt & & \\
\hline \multirow[t]{2}{*}{12} & sun721-F & taagggcatctagggaccaa & 1,003 & 1,003 \\
\hline & $\operatorname{sun} 721-R$ & cctaggttgaccccgttttt & & \\
\hline \multirow[t]{2}{*}{13} & sun $722-F$ & tgtcaaagacttctgaagaaaattg & Null & 1,003 \\
\hline & $\operatorname{sun} 722-R$ & caccgecttcctctactcc & & \\
\hline \multirow[t]{2}{*}{14} & sun $723-F$ & cagagcatggacaaaaagca & 1,022 & 1,022 \\
\hline & $\operatorname{sun} 723-R$ & agctagtgcctttgctctcg & & \\
\hline \multirow[t]{2}{*}{15} & sun $724-F$ & atatgagccgtccattctcg & 1,045 & 1,045 \\
\hline & sun $724-R$ & actcctggttacgccaacac & & \\
\hline \multirow[t]{2}{*}{16} & sun $725-F$ & tggtaccacacgctaagca & $1,035+750$ & 1,035 \\
\hline & sun $725-R$ & gggtggggagtattggaaat & & \\
\hline \multirow[t]{2}{*}{17} & sun $726-F$ & ggcctggtcaagggtacg & 1,012 & 1,012 \\
\hline & sun726- $R$ & gggtggggagtattggaaat & & \\
\hline \multirow[t]{2}{*}{18} & sun $727-F$ & gatgcgtgcattcagttttg & Null & 1,051 \\
\hline & $\operatorname{sun} 727-R$ & cgttcgtagctgttagtagatgtagg & & \\
\hline
\end{tabular}

Table 4. Kompetitive allele-specific polymerase chain reaction (KASP) markers designed for single-nucleotide polymorphism (SNP) detected in sequenced parental sequence-tagged site (STS) amplicons

\begin{tabular}{|c|c|c|c|c|c|}
\hline STS marker & KASP marker & Allele 1 primer ${ }^{a}$ & Allele 2 primer ${ }^{b}$ & Common primer & SNP \\
\hline $\operatorname{sun} 713$ & sunKASP_109 & ggatgtagtttgtcaccagcc & aggatgtagtttgtcaccagca & ggattaacatattcctcgaatgc & {$[\mathrm{C} / \mathrm{A}]$} \\
\hline $\operatorname{sun} 717$ & sunKASP_110 & cgcatttccecttgacc & cgcatttccecttgacg & gcttcccaccettatttcac & {$[\mathrm{C} / \mathrm{G}]$} \\
\hline $\operatorname{sun} 719$ & sunKASP_111 & gccagccaacaagcaac & gccagccaacaagcaag & ttgacatccaaaaccagtgc & {$[\mathrm{C} / \mathrm{G}]$} \\
\hline $\operatorname{sun} 726$ & sunKASP_112 & agcgcgctctcttagcag & agcgcgctctcttagcaa & aaagaggtaatgtgctgacctg & {$[\mathrm{G} / \mathrm{A}]$} \\
\hline $\operatorname{sun} 724$ & sunKASP_113 & ttgctagcttctacggcetg & ttgctagcttctacggectc & tgtgagcagacacaatgcaa & {$[\mathrm{G} / \mathrm{C}]$} \\
\hline
\end{tabular}

a A1 primer labeled with FAM: GAAGGTGACCAAGTTCATGCT.

b A2 primer labeled with HEX: GAAGGTCGGAGTCAACGGATT. 
three STS markers derived from the scaffold-77836 cosegregated with $\operatorname{Yr} 34$. The awn inhibitor allele $B 1$ is not completely linked to $Y r 34$ but is sufficiently close $(<1 \mathrm{cM})$ to be used as an effective morphological marker to select for $\operatorname{Yr} 34$ in the field. In areas where awned cultivars are preferred, prebreeding might be used to produce awned recombinants between $B 1$ and $Y r 34$ for use in breeding. Alternatively, RIL143 is awned and could be used as an awned source of Yr34/Yr48.

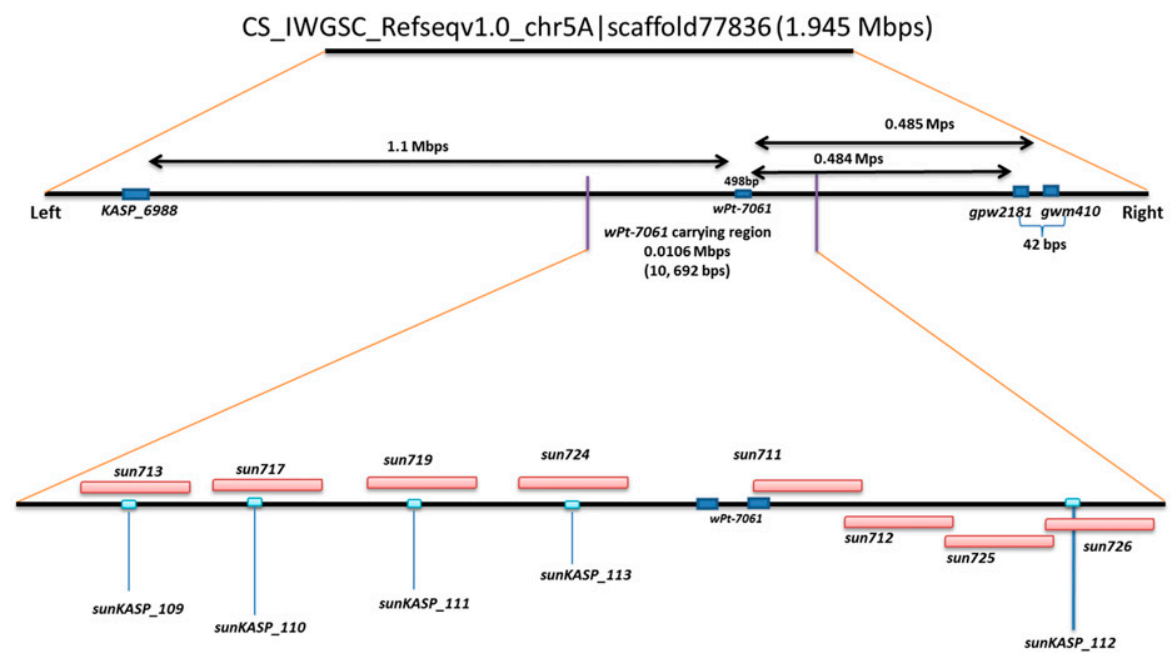

Fig. 3. Diagrammatic representation of positions of Yr34-linked markers in International Wheat Genome Sequencing Consortium scaffold-77386.

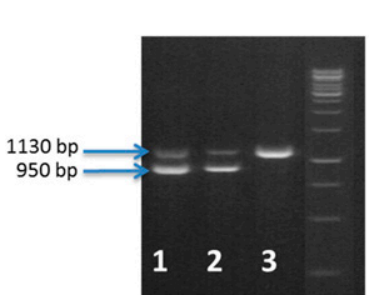

sun 711

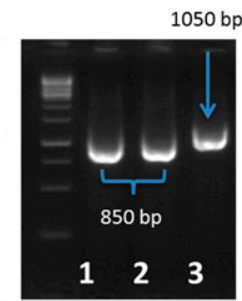

sun 712

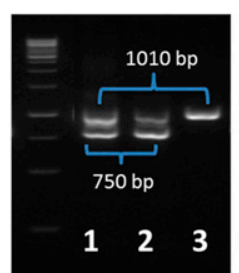

sun 725

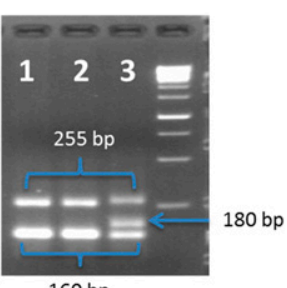

$160 \mathrm{bp}$

gpw 2181

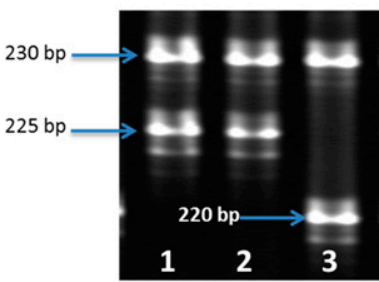

cfa2149

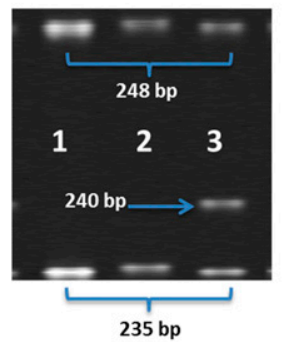

gwm410

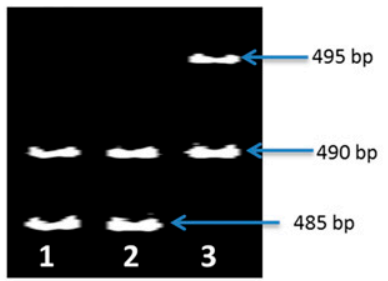

wPt-7061

Fig. 4. Polymorphism of Yr34-linked markers among genotypes WAWHT2046-Yr34 (lane 1), RIL143-Yr48 (lane 2), and Carnamah (lane 3, susceptible control).

Table 5. Haplotype diversity of $Y r 34$-linked markers in Australian cultivars and the $Y r 48$ stock RIL143

\begin{tabular}{|c|c|c|c|c|c|c|c|c|c|}
\hline \multirow[b]{2}{*}{ Genotypes } & \multicolumn{2}{|c|}{ Allele } & \multicolumn{7}{|c|}{ Base pairs } \\
\hline & sunKASP_109 & sunKASP_112 & sun712 & $w P t-7061$ & $c f a 2149$ & $\operatorname{sun} 711$ & $\operatorname{sun} 725$ & gwm410 & $g p w 2181$ \\
\hline WAWHT2046 (Yr34) & A:A & A:A & 850 & $485+490$ & $225+230$ & $1,130+950$ & $1,010+750$ & $235+$ null +248 & $160+$ null +255 \\
\hline RIL143 (Yr48) & $\mathrm{A}: \mathrm{A}$ & A:A & 850 & $485+490$ & $225+230$ & $1,130+950$ & $1,010+750$ & $235+$ null +248 & $160+$ null +255 \\
\hline Carnamah & $\mathrm{C}: \mathrm{C}$ & $\mathrm{G}: \mathrm{G}$ & 1,050 & $490+495$ & $220+230$ & 1,130 & 1,010 & $235+240+248$ & $160+180+255$ \\
\hline Avocet S & $\mathrm{C}: \mathrm{C}$ & G:G & 1,050 & $490+495$ & $220+230$ & 1,130 & 1,010 & $235+240+248$ & $160+180+255$ \\
\hline Orion & A:A & A:A & 1,050 & $490+495$ & $220+230$ & 1,130 & 1,010 & $235+240+248$ & $160+180+255$ \\
\hline AGT Katana + & $\mathrm{C}: \mathrm{C}$ & G:G & 1,050 & $490+495$ & $220+230$ & 1,130 & 1,010 & $235+240+248$ & $160+180+255$ \\
\hline
\end{tabular}

69 others $^{\mathrm{a}}$

a Other genotypes: Axe, Baxter, Bolac, Calingiri, Catalina, Chara, Cobra, Corack, Correll, Crusader, Dart, Derrimut, Diamondbird, EGA Bonnie Rock, EGA Bounty, EGA Burke, EGA Gregory, EGA Wedgetail, EGA Wylie, Elmore CL Plus, Emu Rock, Envoy, Espada, Estoc, Forrest, Fortune, Gauntlet, Gazelle, GBA Sapphire, Giles, Gladius, Grenade CL Plus, Impala, Impose CL Plus, Janz, Justica CL Plus, King Rock, Kord CL Plus, Kunjin, Lang, Lincoln, Livingston, Mace, Magenta, Merinda, Merlin, Phantom, Preston, Scout, Sentinel, Shield, Spitfire, Strezlecki, Sunco, Sunguard, Suntop, Sunvale, Sunvex, Sunzell, Ventura, Waagan, Wallup, Wedin, Westonia, Wyalkatchem, Wylah, Yandanooka, Yitpi, and Young. 
Yr48 was originally assigned a different name from $Y r 34$ based on the complete linkage of $Y r 48$ with marker $g w m 410$ and the initial mapping of Yr34 $20.4 \mathrm{cM}$ proximal to gwm410 (Bariana et al. 2006) (Fig. 2A). Marker gwm410 amplifies alleles on other group 5 homeologs and it is possible that genotypic misclassification caused the higher estimated genetic linkage with $\operatorname{Yr} 34$ in the original study. In this study, gwm410 was completely linked to $Y r 34$ (Fig. 2B and C), similarly to what was reported for $\mathrm{Yr} 48$ (Lowe et al. 2011). Based on the complete linkage with the same subset of molecular markers, the identical alleles displayed by these markers in wheat genotypes carrying $\mathrm{Yr} 34$ and $Y r 48$, the absence of susceptible segregants among $600 \mathrm{~F}_{2}$ plants from a cross between WAWHT2046 (Yr34) and RIL143 (Yr48), and the identical resistance response (IT 23C-3C) to post-2000 P. striiformis f. sp. tritici pathotypes exhibited by the two genes at the two-leaf stage (Fig. 1), we concluded that $\mathrm{Yr} 34$ and $\mathrm{Yr} 48$ represent the same resistance gene. Because the $Y r 34$ name has precedence over $Y r 48$, we propose to designate $Y r 48$ as a synonym of $Y r 34$.

The markers developed in this study can be used for efficient marker-assisted pyramiding of $Y r 34$ or Yr48 with other marker-tagged genes such as Yr51 (Randhawa et al. 2014), Yr57 (Randhawa et al. 2015), $\operatorname{Yr} 58$ (Chhetri et al. 2016), $\operatorname{Yr} 71$ (Bariana et al. 2016), Lr48 (Nsabiyera et al. 2016), Sr2 (Mago et al. 2011), Sr22 (Periyannan et al. 2011), Sr45 (Periyannan et al. 2014), Sr56 (Bansal et al. 2014), Yr47/Lr52 (Qureshi et al. 2017), Lr34/Yr18/Pm38 (Lagudah et al. 2006), Lr57/Yr40 (Kuraparthy et al. 2007), Lr67/Yr46 (Moore et al. 2015), Lr76/Yr40 (Bansal et al. 2017), and Sr39/Lr35 (Mago et al. 2009) to produce triple rust-resistant cultivars carrying combinations of seedling and adult-plant resistance genes.

Continual improvements to the assembly quality and annotation of the bread wheat reference genome is accelerating the rate at which markers closely linked to a trait of interest can be developed and reducing the effort required to clone the underlying gene. An interesting candidate gene identified in the region linked to Yr34 is bHLH-MYC_N (pfam14215), a member of superfamily cl16716 (PSSM ID: 327206) located in scaffold-77836. This gene is known to regulate the biosynthesis of phenylpropanoids (https://www.ncbi.nlm.nih.gov/Structure/ cdd/wrpsb.cgi), which influence plant responses to a number of stresses (Vogt 2010) and play a key role in promoting plant resistance to pests (La Camera et al. 2004). Further experimental work will be required to elucidate the causal gene for $\operatorname{Yr} 34$.

\section{Acknowledgments}

N. Qureshi acknowledges the University of Sydney for a USydIS award to pursue Ph.D. studies. We thank the Grains Research and Development Corporation, Australia for financial support through the Australian Cereal Rust Control Program; IWGSC for making the NRGene genome assembly of Chinese Spring available under the Toronto Agreement; and S. Hoxha and H. Miah for technical support.

\section{Literature Cited}

Bansal, M., Kaur, S., Dhaliwal, H., Bains, N., Bariana, H., Chhuneja, P., and Bansal, U. 2017. Mapping of Aegilops umbellulata-derived leaf rust and stripe rust resistance loci in wheat. Plant Pathol. 66:38-44.

Bansal, U., Bariana, H., Wong, D., Randhawa, M., Wicker, T., Hayden, M., and Keller, B. 2014. Molecular mapping of an adult plant stem rust resistance gene Sr56 in winter wheat cultivar Arina. Theor. Appl. Genet. 127:1441-1448.

Bansal, U. K., Hayden, M. J., Gill, M. B., and Bariana, H. S. 2010. Chromosomal location of an uncharacterised stripe rust resistance gene in wheat. Euphytica 171:121-127.

Bariana, H., Forrest, K., Qureshi, N., Miah, H., Hayden, M., and Bansal, U. 2016. Adult plant stripe rust resistance gene $\operatorname{Yr} 71$. Mol. Breed. 36:98.

Bariana, H. S., Miah, H., Brownm, G. N., Willey, N., and Lehmensiek, A. 2007. Molecular mapping of durable rust resistance in wheat and its implication in breeding. Pages 723-728 in: Wheat Production in Stressed Environments.

H. T. Buck, J. E. Nisi, and N. Salomón, eds. Springer Netherlands, Dordrecht, The Netherlands.

Bariana, H. S., Parry, N., Barclay, I. R., Loughman, R., McLean, R. J., Shankar, M., Wilson, R. E., Willey, N. J., and Francki, M. 2006. Identification and characterization of stripe rust resistance gene $\mathrm{Yr} 34$ in common wheat. Theor. Appl. Genet. 112:1143-1148.

Chen, W., Wellings, C., Chen, X., Kang, Z., and Liu, T. 2014. Wheat stripe (yellow) rust caused by Puccinia striiformis f. sp. tritici. Mol. Plant Pathol. $15: 433-446$

Chen, X. 2005. Epidemiology and control of stripe rust [Puccinia striiformis f. sp. tritici] on wheat. Can. J. Plant Pathol. 27:314-337.
Chhetri, M., Bariana, H., Kandiah, P., and Bansal, U. 2016. Yr58: A new stripe rust resistance gene and its interaction with $\mathrm{Yr} 46$ for enhanced resistance. Phytopathology 106:1530-1534.

He, J., Zhao, X., Laroche, A., Lu, Z. X., Liu, H., and Li, Z. 2014. Genotypingby-sequencing (GBS), an ultimate marker-assisted selection (MAS) tool to accelerate plant breeding. Front. Plant Sci. 5:484.

Hovmøller, M. S., and Bayles, R. 2005. Recent history of cereal rust control in Europe. Page 47 in: Proc. Global Landscapes Cereal Rust Control. An international forum to mark the contribution of Prof R. A. McIntosh to the genetics of cereal rust control. Katoomba, Australia.

International Wheat Genome Sequencing Consortium. 2014. A chromosome-based draft sequence of the hexaploid bread wheat genome. Science 345:1251788.

Koressaar, T., and Remm, M. 2007. Enhancements and modifications of primer design program Primer3. Bioinformatics 23:1289-1291.

Kosambi, D. D. 1943. The estimation of map distances from recombination values. Ann. Eugen. 12:172-175.

Kuraparthy, V., Chhuneja, P., Dhaliwal, H. S., Kaur, S., Bowden, R. L., and Gill, B. S. 2007. Characterization and mapping of cryptic alien introgression from Aegilops geniculata with new leaf rust and stripe rust resistance genes Lr57 and Yr40 in wheat. Theor. Appl. Genet. 114:1379-1389.

La Camera, S., Gouzerh, G., Dhondt, S., Hoffmann, L., Frittig, B., Legrand, M., and Heitz, T. 2004. Metabolic reprogramming in plant innate immunity: The contributions of phenylpropanoid and oxylipin pathways. Immunol. Rev. 198:267-284.

Lagudah, E. S., McFadden, H., Singh, R. P., Huerta-Espino, J., Bariana, H. S., Spielmeyer, W. 2006. Molecular genetic characterization of the Lr34/Yr18 slow rusting resistance gene region in wheat. Theor. Appl. Genet. 114:21-30.

Lowe, I., Jankuloski, L., Chao, S., Chen, X., See, D., and Dubcovsky, J. 2011 Mapping and validation of QTL which confer partial resistance to broadly virulent post-2000 North American races of stripe rust in hexaploid wheat. Theor. Appl. Genet. 123:143-157.

Mago, R., Tabe, L., McIntosh, R., Pretorius, Z., Kota, R., Paux, E., Wicker, T., Breen, J., Lagudah, E., and Ellis, J. 2011. A multiple resistance locus on chromosome arm 3BS in wheat confers resistance to stem rust ( $\mathrm{Sr} 2)$, leaf rust (Lr27) and powdery mildew. Theor. Appl. Genet. 123:615-623.

Mago, R., Zhang, P., Bariana, H. S., Verlin, D. C., Bansal, U. K., Ellis, J. G., and Dundas, I. S. 2009. Development of wheat lines carrying stem rust resistance gene Sr39 with reduced Aegilops speltoides chromatin and simple PCR markers for marker-assisted selection. Theor. Appl. Genet. 119:1441-1450.

Manly, K. F., Cudmore, R. H., Jr., and Meer, J. M. 2001. Map Manager QTX cross-platform software for genetic mapping. Mamm. Genome 12:930-932.

McIntosh, R. A., Wellings, C. R., and Park, R. F. 1995. Wheat Rusts: An Atlas of Resistance Genes. CSIRO Publishing, Melbourne, Australia.

Moore, J. W., Herrera-Foessel, S., Lan, C., Schnippenkoetter, W., Ayliffe, M., Huerto-Espino, J., Lillemo, M., Viccars, L., Periyannan, S., Kong, X., Spielmeyer, W., Talbot, M., Bariana, H., Patrick, J. W., Dodds, P., Singh, R., and Lagudah, E. 2015. A recently evolved hexose transporter variant confers resistance to multiple pathogens in wheat. Nat. Genet. 47:1494-1498.

Nsabiyera, V., Qureshi, N., Bariana, H. S., Wong, D., Forrest, K. L., Hayden, M. J., and Bansal, U. 2016. Molecular markers for adult plant leaf rust resistance gene Lr48 in wheat. Mol. Breed. 36:65

O'Brien, L., Brown, J., Young, R., and Pascoe, I. 1980. Occurrence and distribution of wheat stripe rust in Victoria and susceptibility of commercial wheat cultivars. Australas. Plant Pathol. 9:14.

Periyannan, S., Bansal, U., Bariana, H., Deal, K., Luo, M. C., Dvorak, J., and Lagudah, E. 2014. Identification of a robust molecular marker for the detection of the stem rust resistance gene $\mathrm{Sr} 45$ in common wheat. Theor. Appl. Genet. 127:947-955.

Periyannan, S., Bansal, U. K., Bariana, H. S., Pumphrey, M., and Lagudah, E. S. 2011. A robust molecular marker for the detection of shortened introgressed segment carrying the stem rust resistance gene $\mathrm{Sr} 22$ in common wheat Theor. Appl. Genet. 122:1-7.

Qureshi, N., Bariana, H., Forrest, K., Hayden, M., Keller, B., Wicker, T., Faris, J., Salina, E., and Bansal, U. 2017. Fine mapping of the chromosome 5B region carrying closely linked rust resistance genes $\mathrm{Yr} 47$ and $\mathrm{Lr} 52$ in wheat. Theor. Appl. Genet. 130:495-504.

Randhawa, M., Bansal, U., Valarik, M., Klocova, B., Dolezel, J., and Bariana, H. 2014. Molecular mapping of stripe rust resistance gene $\mathrm{Yr} 51$ in chromosome 4AL of wheat. Theor. Appl. Genet. 127:317-324.

Randhawa, M. S., Bariana, H. S., Mago, R., and Bansal, U. K. 2015. Mapping of a new stripe rust resistance locus Yr57 on chromosome 3BS of wheat. Mol. Breed. 35:65

Röder, M. S., Korzun, V., Wendehake, K., Plaschke, J., Tixier, M. H., Leroy, P., and Ganal, M. W. 1998. A microsatellite map of wheat. Genetics 149:2007-2023.

Singh, B., Bansal, U. K., Forrest, K. L., Hayden, M. J., Hare, R. A., and Bariana, H. S. 2010. Inheritance and chromosome location of leaf rust resistance in durum wheat cultivar Wollaroi. Euphytica 175:351-355.

Somers, D. J., Isaac, P., and Edwards, K. 2004. A high-density microsatellite consensus map for bread wheat (Triticum aestivum L.). Theor. Appl. Genet. 109:1105-1114.

Sourdille, P., Guyomarc'h, H., Baron, C., Gandon, B., Chiquet, V., Artiguenave, F., Edwards, K., Foisset, N., Dufour, P., and Bernard, M. 2001. Improvement of the genetic maps of wheat using new microsatellite markers. Plant Anim. Genome. IX: Abstract 167 
Untergasser, A., Cutcutache, I., Koressaar, T., Ye, J., Faircloth, B. C., Remm, M., and Rozen, S. G. 2012. Primer3-New capabilities and interfaces. Nucleic Acids Res. 40:e115.

Vogt, T. 2010. Phenylpropanoid biosynthesis. Mol. Plant 3:2-20.

Voorrips, R. 2002. MapChart: Software for the graphical presentation of linkage maps and QTLs. J. Hered. 93:77-78.

Wang, S., Wong, D., Forrest, K., Allen, A., Chao, S., Huang, B. E., Maccaferri, M., Salvi, S., Milner, S. G., Cattivelli, L., Mastrangelo, A. M., Whan, A., Stephen, S., Barker, G., Wieseke, R., Plieske, J., International Wheat Genome Sequencing Consortium, Lillemo, M., Mather, D., Appels, R., Dolferus, R., Brown-Guedira, G., Korol, A., Akhunova, A. R., Feuillet, C., Salse, J., Morgante, M., Pozniak,
C., Luo, M. C., Dvorak, J., Morell, M., Dubcovsky, J., Ganal, M., Tuberosa, R., Lawley, C., Mikoulitch, I., Cavanagh, D., Edwards, K. J., Hayden, M., and Akhunov, E. 2014. Characterization of polyploid wheat genomic diversity using a high-density 90,000 single nucleotide polymorphism array. Plant Biotechnol J. 12:787-796.

Wellings, C. 2007. Puccinia striiformis in Australia: A review of the incursion, evolution, and adaptation of stripe rust in the period 1979-2006. Crop Pasture Sci. 58:567-575.

Wellings, C., Wright, D., Keiper, F., and Loughman, R. 2003. First detection of wheat stripe rust in Western Australia: Evidence for a foreign incursion. Australas. Plant Pathol. 32:321-322. 